http://dx.doi.org/10.18675/1981-8106.vol26.n51.p36-48

\title{
Representações sociais de discentes universitários sobre disciplinas de Educação Física no curso de Pedagogia
}

\author{
Social representations of university students about subjects of Physical \\ Education in the Faculty of Education
}

\section{Representaciones sociales de discentes universitarios sobre disciplinas de Educación Física en el curso de Pedagogía}

\author{
Ramon Missias Moreira' \\ Anderson de Souza Santos" \\ Edvaldo Souza Couto"I \\ ' Universidade Federal da Bahia (UFBA), Bahia - Brasil. E-mail: ramonefisica@hotmail.com \\ "Universidade Estadual do Sudoeste da Bahia (UESB), Bahia - Brasil. E-mail: anderson- \\ uesbedfisica@hotmail.com \\ III Universidade Federal da Bahia (UFBA), Bahia - Brasil. E-mail: edvaldosouzacouto@gmail.com
}

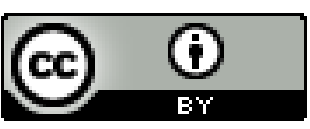

Educação: teoria e prática, Rio Claro, SP, Brasil - eISSN: 1981-8106

Está licenciada sob Licença Creative Common

\section{Resumo}

Esta investigação científica objetivou identificar as representações sociais de discentes do Curso de Pedagogia da Universidade Estadual do Sudoeste da Bahia (UESB) sobre as disciplinas EF I, II e III e, analisar a influência das disciplinas EF I, II e III na formação acadêmica desses discentes. Trata-se de um estudo descritivo-exploratório, qualitativo e que ancorou-se na Teoria das Representações Sociais. Após Aprovação do Comitê de Ética em Pesquisa, participaram da entrevista semiestruturada 38 discentes do Curso de Pedagogia da UESB, tendo suas evocações sido analisadas a partir da técnica de análise de conteúdo. As unidades de análise foram agrupadas em 3 categorias que expressam representações dos estudantes universitários sobre os componentes curriculares EF I, II e III, a saber: 
Representações Positivas da Educação Física; Educação Física como Lazer; e, Influência na (in)Formação Acadêmica. Desta forma, concluímos que os componentes curriculares, da forma como foram apresentados, solidificaram as representações sociais dos alunos, de forma aos mesmos apresentarem em suas manifestações vários aspectos que revelam que, por vezes, as disciplinas não foram tratadas com a importância devida, demonstrando a ausência do valor desses componentes em sua formação acadêmica.

Palavras-chave: Educação Física; Representações Sociais; Discentes.

\begin{abstract}
This scientific research aimed to identify the social representations of Pedagogy students at State University of Southwest Bahia (UESB) on PE I, II and III courses, and analyze the influence of disciplines PE I, II and III in the academic education of these students. The study is a descriptive, exploratory, qualitative and anchored on the Theory of Social Representations study. After the approval by the Ethics in Research Committee participated in the semi-structured interview 38 students of the School of Education at UESB. The evocations were analyzed by using the technique of content analysis. The units of analysis were grouped into three categories that express representations of college students on the curricular components PE I, II and III, namely: Positive Representations of Physical Education; Physical Education and Recreation; and Influence in the (in) Academic Training. Thus, we conclude that the curriculum components, the way they were presented, solidified the social representations of students to present themselves in their various manifestations, revealing aspects that sometimes are not treated with expected importance by the subjects, demonstrating the absence of the value of these components in their academic training.
\end{abstract}

Keywords: Physical Education; Social Representations; Students.

\title{
Resumen
}

Esta investigación científica tuvo como objetivo identificar las representaciones sociales de discentes del Curso de Pedagogía de la Universidade Estadual do Sudoeste da Bahia (UESB) sobre las disciplinas EF I, II y III; y, analizar la influencia de las disciplinas EF I, II y III en la formación académica de esos discentes. Se trata de un estudio descriptivo-exploratorio y cualitativo, que se basó en la Teoría de las Representaciones Sociales. Tras la Aprobación del Comité de Ética en Investigación, participaron de la entrevista semiestructurada 38 discentes del Curso de Pedagogía de la UESB, siendo analizadas sus evocaciones a partir de la técnica de análisis de contenido. Las unidades de análisis se agruparon en 3 categorías que expresan las representaciones de los estudiantes universitarios sobre los componentes curriculares EF I, II y III, a saber: Representaciones Positivas de la Educación Física; Educación Física como Ocio; e, Influencia en la (in)Formación Académica. De esta forma, concluimos que de 
la manera como se presentaron los componentes curriculares, estos solidificaron las representaciones sociales de los alumnos, de forma que los mismos presentaron en sus manifestaciones varios aspectos que revelan que, a veces, las disciplinas no se trataron con la importancia debida, demostrando la ausencia de valor de estos componentes en su formación académica.

Palabras clave: Educación Física; Representaciones Sociales; Discentes.

\section{Introdução}

Esta pesquisa direciona sua atenção para as Representações Sociais de professores em formação inicial do Curso de Pedagogia da Universidade Estadual do Sudoeste da Bahia (UESB) sobre as disciplinas Educação Física I, II e III (EF I, II e III). O Departamento de Saúde da UESB oferece essas disciplinas para o Curso de Pedagogia, possuindo uma característica de prática esportiva a fim de proporcionar uma diversidade de ações e atividades aos discentes, com o intuito de aumentar o repertório motor e alargar o conhecimento sobre os elementos que envolvem a cultura corporal de movimento.

"Estas disciplinas são conhecidas no meio acadêmico como práticas desportivas (PD), sendo disciplinas baseadas nos mais variados esportes, tendo como forte característica o fato de proporcionar aulas basicamente práticas. A Educação Física, com certeza, tem os mais variados caminhos a seguir, que precisam ser traçados no contexto universitário, o que vai de certa forma depender dos diversos atores sociais envolvidos neste cenário. Entretanto, é preciso que consigamos superar o paradigma da obrigatoriedade em busca de novos horizontes, onde a Educação Física se constitua como direito do estudante à cultura corporal dentro da Universidade (DE PAULA; FARIA, 1998).

Nessa perspectiva, precisamos de uma Educação Física no $3^{\mathrm{a}}$ grau que seja formadora de sujeitos críticos e participantes da sociedade, influenciando de forma conscientizadora na formação de seus alunos, possibilitando aos mesmos uma visão critica dos fatos.

Mesmo com os possíveis defeitos, esta área do conhecimento não deixa de ser importante para os alunos, pois ela tem a capacidade de proporcionar profundas mudanças no estilo de vida dos mesmos, podendo ser o pontapé inicial para uma vida mais ativa fisicamente. Pois estes mesmos alunos podem não ter experiência com a prática de exercícios físicos tornando as disciplinas EF I, II e III uma das únicas oportunidades destes alunos praticarem exercícios.

Desta forma, apesar de muitas vezes ocorrer a desvalorização das disciplinas pelos alunos, as disciplinas Educação Física I, II e III se demonstram muito importantes, pois proporcionam novas experiências aos alunos, demonstrando que esta área do conhecimento 
pode trazer uma infinidade de benefícios tanto para sua formação profissional quanto para outros aspectos de suas vidas.

De acordo com Bordieu (1983), o indivíduo, no decorrer de sua trajetória, dependendo de suas condições materiais e sociais de existência, pode vir a acumular, por meio do ambiente onde vive, das pessoas com quem se relaciona, das práticas sociais que realiza, dentre outras experiências, o capital cultural. Este passa a ser incorporado pelo indivíduo como herança cultural e social, transmitida por sua família ao longo da trajetória de vida.

A partir dessas premissas, resolvemos desenvolver esta investigação científica com os objetivos de identificar as representações sociais de discentes do Curso de Pedagogia da UESB sobre as disciplinas EF I, II e III; e, analisar a influência das disciplinas EF I, II e III na formação acadêmica desses discentes.

\section{Aporte teórico: Teoria das Representações Sociais (TRS)}

A TRS teve seu início na França, na década de 50, quando o psicólogo social Serge Moscovici buscou em seus estudos entender como a psicanálise, um novo saber especializado, era compreendido pela sociedade francesa naquela época. A partir desse estudo, ele conseguiu compreender como um objeto científico torna-se objeto do senso comum. Este trabalho foi publicado em sua obra "A psicanálise, sua imagem e seu público", que lhe concedeu o titulo de "criador da teoria das representações sociais" (MOSCOVICI,1978).

Conforme Alves Mazzotti (2002), Moscovici inicia esse processo de elaboração teórica retomando o conceito de representação coletiva, proposto por Durkheim. Esta noção de representação social proposta por Moscovici corresponde à busca desta especificidade, através da elaboração de um conceito verdadeiramente psicossocial, na medida em que procura dialetizar as relações entre indivíduo e sociedade, afastando-se igualmente da visão sociologizante de Durkheim e da perspectiva psicologizante da Psicologia Social da época.

Apesar de ter uma visão diferente diante dos fatos, Durkheim definiu passos importantes para a construção do conhecimento científico, à medida que delimitou a percepção do coletivo como princípio de nossa vida e nossa história a partir das produções mentais sociais, caracterizando-se como representações sociais e coletivas (MOSCOVICI, 2009; AZEVEDO et al, 2012). Porém, observa-se que as percepções, atitudes, opiniões e imagens não dão conta de ressaltar o papel das ligações, interações e relações entre os seres humanos; nem consideram os contextos, intenções, propensões e critérios utilizados pelos atores sociais (MOSCOVICI, 2009).

Encontra-se na literatura diversas definições e concepções acerca desta teoria, onde uma concepção que tem sido aceita por grande parte dos pesquisadores é o sentido proposto por Jodelet (2001) à TRS, demarcando as representações sociais como uma maneira de 
apreender o conhecimento socialmente elaborado e partilhado, sob o olhar prático, voltado para a construção de uma realidade em comum a determinado conjunto social.

Segundo Jodelet (2001), as representações sociais são uma forma de conhecimento socialmente organizado e partilhado, que tem objetivo prático e colabora para a constituição de uma realidade comum a um grupo social, podendo ser denominada como saber de senso comum ou ainda saber natural. Esta forma de conhecimento é distinta, entre outras, do conhecimento cientifico. Entretanto, é tida como um objeto de estudo legítimo da própria ciência. Apresenta relevância para a vida social já que indica processos cognitivos encarnados nas interações sociais.

De acordo Mazzotti (2002) sujeito e objeto não são funcionalmente distintos, eles formam um conjunto indissociável. Isso quer dizer que um objeto não existe por si mesmo, mas apenas em relação a um sujeito (indivíduo ou grupo); é a relação sujeito-objeto que determina o próprio objeto. Ao formar sua representação de um objeto, o sujeito, de certa forma, o constitui, o reconstrói em seu sistema cognitivo, de modo a adequá-lo aos seus sistemas de valores, o qual, por sua vez, depende de sua história e do contexto social e ideológico no qual está inserido.

Nesse panorama, podemos concordar com Leontiev (1978), quando afirma que as representações sociais são comportamentos em miniatura. Por esta razão, atribuímos- lhe uma virtude preditiva, uma vez que, segundo que um indivíduo diz, não apenas podemos inferir suas concepções de mundo, como também podemos deduzir sua orientação para a ação.

As representações sociais são uma "modalidade de conhecimento particular que tem por função a elaboração de comportamentos e a comunicação entre indivíduos" (MOSCOVICI, 1978, p. 26).

O mesmo nos direciona na mesma linha de pensamento quando diz: a representação social, portanto, não é uma cópia nem um reflexo, uma imagem fotográfica da realidade: é uma tradução, uma versão desta. Ela está em transformação como o objeto que tenta elaborar. É uma dinâmica, móvel. Ao mesmo tempo, diante da enorme massa de traduções que executamos continuamente, constituímos uma sociedade de sábios amadores (MOSCOVICI, 1961).

Essa reapropriação do passado pelo contemporâneo ocorre em um processo dinâmico em que cada geração altera o sentido e a compreensão dos conhecimentos preexistentes. $\mathrm{Ou}$ seja, cada contexto atual seleciona um conteúdo do passado que vai ser reatualizado, por meio de um recorte e de uma interpretação própria dependentes, em última instância, do sentido que um determinado grupo irá atribuir ao seu "espaço de experiência" e "horizonte de expectativa" (KOSELLECK, 2006).

As representações sociais dizem respeito ao processo de construção e reconstrução da realidade, operada pelos grupos humanos. Elas têm ainda a 
função de tornar familiar o estranho, no sentido de uma aproximação cognitiva (KOSELLECK, 2006, p. 55).

Essa aproximação ocorre por meio dos processos de ancoragem e objetivação. A objetivação, segundo Almeida (2001, p. 131), "torna concreto o que é abstrato. Ela transforma um conceito em uma imagem de uma coisa, retirando-o de seu quadro conceitual científico". A ancoragem diz respeito ao processo de familiarização através do apoio em conhecimentos anteriores. É esse conhecimento já apropriado que permite dar sentido ao novo.

\section{Método}

Trata-se de uma pesquisa qualitativa (MINAYO; DESLANDES; GOMES, 2012) e optamos por este delineamento de estudo por acreditarmos que ela atende aos interesses da pesquisa, respondendo aos questionamentos levantados, numa profunda imersão nas relações e fatores que influenciam, considerando como participantes da investigação científica pessoas que fazem parte de determinada situação social, com crenças, valores, experiências e significados.

Nesse sentido, trata-se de um estudo de cunho descritivo e exploratório, o qual favorece delinear amplos aspectos de determinada realidade social, permitindo esclarecer as variadas formas dos fenômenos, analisando a luz da causa e efeito dos fatos (MINAYO, 2012), pois é a partir de como os sujeitos compreendem o mundo, que eles se constroem e transformam a si mesmo. Essa pesquisa ancorou-se na Teoria das Representações Sociais (MOSCOVICI, 2009), demarcando as representações sociais dos discentes como uma maneira de apreender o conhecimento socialmente elaborado e partilhado, sob o olhar prático, voltado para a construção de uma realidade em comum a determinado grupo de pertença.

A pesquisa foi realizada na Universidade Estadual do Sudoeste da Bahia, campus de Jequié, entre setembro de 2013 e maio de 2014. Levando-se em consideração o caráter e os objetivos desta pesquisa e o critério de saturação (FONTANELLA; RICAS; TURATO, 2008), participaram da entrevista semiestruturada 38 discentes do Curso de Licenciatura em Pedagogia da UESB, que cursaram as disciplinas Educação Física I, II e III no período entre 2009 e 2013.

Desse modo, os participantes foram determinados a partir da identificação de repetição de informações nos depoimentos, a partir do instante em que os resultados de formatos mais consistentes e coesos demonstraram informações redundantes e repetitivas (FONTANELLA; RICAS; TURATO, 2008). Utilizamos a Técnica de Análise de Conteúdo Categorial (BARDIN, 2011) para analisar as entrevistas, obedecendo aos critérios de pré-análise, exploração do material, tratamento dos dados, inferência e interpretação. Ao final de cada recorte realizado nas falas dos acadêmicos está indicado entre parênteses um elemento alfanumérico (D1, D2, D3, etc) que identifica o participante. 
Nesse panorama, buscando atender aos preceitos éticos da pesquisa com seres humanos, que estão preconizados na Resolução 466/2012 do Conselho Nacional de Saúde, a pesquisa obteve parecer de aprovada pelo Comitê de Ética em Pesquisa da UESB (CEP/UESB) tendo como número do CAAE: 23246113.0.0000.0055. A coleta de dados se deu após a assinatura do Termo de Consentimento Livre e Esclarecido pelos participantes.

\section{Resultados e discussão}

\section{Representações Positivas da Educação Física}

A categoria Representações Positivas da Educação Física, neste estudo, é referente às percepções dos discentes universitários com relação às disciplinas EF I, II e III, oferecidas na grade curricular do Curso de Licenciatura em Pedagogia da UESB.

Conforme os recortes apresentados abaixo se observa nos mesmos a sustentação para essa classe temática, que foi composta por 13 unidades sentido.

[...] tinha aquela coisa pela saúde, pelo preparo físico, foi uma coisa feita assim com muita seriedade, muita disposição mesmo, satisfatório [...] eu acho ela boa porque ela me ajuda no meu condicionamento físico (D6). [...] $\mathrm{Eu}$ acho importante porque nos transmite uma vida de qualidade, e nos direciona ao exercício físico, a prática do exercício (D7). [...] eu tava muito sedentária e agora eu quero continuar nessa linha assim, de fazer algum exercício porque o joelho agradece (D8). [...] Educação Física é uma disciplina interessante que irá nos ajudar no nosso condicionamento físico (D9). [...] essas disciplinas Educação Física I, II, III inicia isso, dá esse pontapé inicial, para os alunos continuarem praticando os exercícios e ficando bem com sua saúde (D13). [...] a importância de praticar esporte na vida, a questão de saudável mesmo (D14). [...] a gente fez atividade de academia e agora natação, ai pra mim está sendo bem legal pro meu corpo (D29). [...] ela vai trazer pra gente a questão de educar o corpo pra saúde, a gente, todo mundo que tá com saúde pode render mais né? (D31). [...] dá até mais força de vontade pra você continuar fazendo atividade física mesmo depois que termina a disciplina (D32). [...] É uma coisa que a gente leva pra vida, quem é que não quer saber os benefícios que a Educação Física nos propõe? (D34). [...] é como se fosse uma academia (D37). [...] eu achei que é bom o acompanhamento do aluno dentro da universidade, um acompanhamento físico (D36).

Foi possível observar nesta categoria que os discentes entenderam as disciplinas como importantes para a sua iniciação esportiva, para o seu condicionamento físico e até mesmo para sua saúde de uma forma geral. Neste sentido, esta categoria demonstra que os mesmos concebem a Educação Física como de fundamental importância e relevância pelo incentivo à prática/execução da atividade física, proporcionando benefícios à vida dos estudantes, apresentando-se como necessária para a vida e para a formação humana dos mesmos. 
Nesse contexto, a educação integral da pessoa perpassa pelas dimensões social, física, intelectual e cognitiva. A iniciação esportiva é tão importante quanto qualquer outro componente curricular, uma vez que o esporte na vida do estudante contribui para sua participação efetiva na sociedade, melhorando suas relações sociais, seu condicionamento físico, sua autoestima; juntamente com os vários benefícios que uma prática regular e orientada de exercícios físicos pode proporcionar, o que está amplamente disposto na literatura. Segundo os autores El-Gilany, et. al. (2011) e Garber, et. al. (2011), o exercício físico é capaz de prevenir e tratar mais de 40 doenças crônicas, produz sensação de bem-estar, aumenta a integração social e ocupa ativamente o tempo livre.

A Educação Física tem grande importância como componente curricular, pois a mesma tem a capacidade de modificar os alunos em diversos aspectos, possibilitando aos educandos diversas experiências e vivências, que influenciam os aspectos físicos, psicológicos, sociais e motores.

Mauro Betti (1998, p. 25-26) aponta que:

O esporte é a forma, mas rica e adaptada ao nosso tempo de um tipo de experiência de base, canalmente vivida, que permite construir, pela prática e pela reflexão, uma ética de saúde global (...). O esporte é atividade de cultura, na medida em que a noção formal de equilíbrio do corpo e espírito é substituída pela de convergência de todas as tentativas educativas (...); O esporte é um instrumento de cultura e de libertação do homem moderno na medida em que desempenha a função biológica (filogenética) de preservação da saúde (no sentido lato do termo) e a função sociocultural de comunicação e expressão.

Com isso, tais representações nos trouxeram que estas disciplinas realmente influenciaram na vida dos estudantes, proporcionando experiências válidas aos mesmos que demonstraram nas entrevistas que o fato de as disciplinas terem oportunizando uma iniciação esportiva aos discentes acabou melhorando de certa forma o condicionamento físico dos mesmos e consequentemente deu um sinal de alerta para os alunos darem uma maior importância a um estilo de vida mais ativo, fazendo-os perceber os riscos de uma vida sedentária.

\section{Educação Física como Lazer}

Nesta categoria foram encontradas 7 unidades de análise, onde os alunos demonstraram em suas falas que as disciplinas foram uma alternativa de lazer, como está disposto a seguir: 
[...] é uma disciplina que é mais tranquila, né? eu acho importante por isso, porque não é tipo assim como as outras que nos obriga a ler, ler, ler o tempo todo, é mais prática, mais dinâmica (D7). [...] Eu achei muito bom, muito divertido, eu aprendi mais, e me desenvolvi mais (D16). [...] ai ele simplesmente me mandou entrar na piscina, "entra na piscina" bom, água, calor, Jequié é quente, e ai eu entrei na piscina (D27). [...] é a questão do calor, que eu tava querendo tomar banho, mas não em relação mesmo a disciplina (D22). [...] bom humor, mais leveza pra poder lidar com os problemas da faculdade e fora também (D30). [...] então eu acho que é bom pra gente distrair um pouco, com trabalho e atividades pra fazer, a aula se torna até um lazer (D32). [...] vejo a Educação Física como uma disciplina que abrange muitas coisas além do esporte, tem o lazer, entre outras (D38).

Quando o assunto é lazer, grande parte dos estudos que definem o lazer se apropriamda definição de Dumazedier (1973):

... o lazer é um conjunto de ocupações às quais o indivíduo pode entregar-se de livre vontade, seja para repousar, seja para divertir-se, recrear-se e entreter-se ou, ainda, para desenvolver sua informação ou formação desinteressada sua participação social voluntária ou sua livre capacidade criadora após livrar-se ou desembaraçar-se das obrigações profissionais, familiares e sociais.

Desta forma, é possível identificar que os objetivos das disciplinas não poderiam ser o de propiciar atividades de lazer aos educandos, visto que para ser lazer tem que ser uma atividade prazerosa, sem obrigação e com tempo disponível. Devido a esta situação, ancorado nos discursos dos alunos que integram esta categoria, é possível constatar que independente dos objetivos que os professores imaginaram para suas aulas, os alunos tiveram como representações que as disciplinas são mais brandas, mais divertidas, chegando ao ponto de relaciona-las com a sua concepção de lazer.

Porém, o fato deles tratarem a Educação Física como uma prática de lazer, demonstra certa falta de conhecimento dos mesmos sobre a temática lazer; mas, ainda assim, pode ser considerado como um aspecto positivo das disciplinas, pelo simples fato destas atividades consideradas como lazer propiciarem benefícios relevantes.

Nesse sentido, Pylro e Rossetti (2005) acrescentam que as atividades recreativas e de lazer nos dias atuais podem ser consideradas uma necessidade de qualquer pessoa, em qualquer idade, pois estas atividades além de serem prazerosas, também contribuem na facilitação da aprendizagem, colaboram para uma boa saúde mental, facilitam os processos de socialização e comunicação, contribuem no desenvolvimento pessoal, cultural e social, além de ajudar na expressão e na construção do conhecimento. 


\section{Influência na (in)Formação Acadêmica}

A categoria influência na (in)formação acadêmica destaca 21 unidades de análise, que desvelam a relação que as disciplinas tiveram com a formação dos acadêmicos em questão e/ou com a informação num conceito global.

Concordamos com Gonçalves e Azevedo (2010) quando descrevem que na contemporaneidade o currículo não é visto como neutro e sim como uma questão política, pois toda proposta pressupõe escolhas geralmente fundamentadas na realidade educativa.

Nesse contexto, as unidades de sentido que sustentaram esta categoria são:

[...] Eu acho que não influencia muito por que Pedagogia é uma coisa totalmente diferente de Educação Física, a Educação Física a gente vai tá tratando de esporte e Pedagogia a gente fica mais naquela parte teórica (D9). [...] Nenhuma (D11). [...] Nenhuma (D15). [...] influencia assim, na capacitação de novos professores, profissionais bem capacitados para o mercado de trabalho (D16). [...] Nenhuma, pois não me preparou para construção e desenvolvimento da minha formação como futura profissional da educação (D17). [...] Particularmente não me contribuiu em nada (D18). [...] Nenhuma, pela estrutura como foi desenvolvida eu não pude encontrar infelizmente (D19). [...] Nenhuma, nenhuma, nenhuma, nenhuma (D20). [...] até agora nenhuma (D22). [...] eu creio que, como a disciplina foi trabalhada, ela não acrescenta muito (D23.) [...] nenhuma. (D24) [...] Não teve influência.(D25) [...] acho que foi as atividades que o professor propôs, não foi assim tão relevante (D30). [...] Bom, na formação acadêmica nenhuma, sincera e honestamente, na formação acadêmica nenhuma, eu não vi assim, de que forma eu posso, servir tanto na minha vida profissional, quanto pro dia a dia também (D27). [...] Sinceramente, na minha formação acadêmica em especial eu não vejo nenhuma influência (D33). [...] não, pelo menos as aulas que eu tive não me demonstrou isso. As aulas não contribuíram em nada! (D35). [...] A Educação Física I eu não achei muito relevante na minha formação, agora a Educação Física II eu estou gostando (D29). [...] Minha percepção é que foram disciplinas úteis, né, eu aproveitei bastante (D36). [...] pra mim foi positivo, e foi bom porque, não aprendi a nadar, mas me ajudou na respiração, já que eu sinto falta de ar (D37). [...] De certa forma ela influencia, pois como faço Pedagogia devo ser versátil (D38).

Ao observarmos esses depoimentos, percebemos que a grande maioria dos relatos nos revelam que os alunos em suas referências acharam que as disciplinas não influenciaram em nada na sua formação acadêmica, pois em quase todas as evocações aparecem que as disciplinas não tiveram nenhuma influência positiva.

Sá (1998) afirma que toda representação se constituem torno de um objeto e que não há uma representação sem um objeto, porém não é mera cópia da realidade, mas reconstruída e internalizada, isto significa dizer que, ao representar um objeto, o sujeito o reconstrói. 
Desta forma, podemos inferir que a grande maioria dos entrevistados não enxergam as disciplinas como importantes a ponto de influenciar tanto na formação profissional dos mesmos quanto em suas vidas.

Porém, houve 6 citações que indicaram que as disciplinas influenciaram de forma positiva na sua formação acadêmica ou para algum aspecto que irá influenciar na sua vida, em seu cotidiano. Ao observar as representações positivas nesta categoria, identificamos que houve quatro representações que demonstraram que as disciplinas influenciaram na sua formação acadêmica e o restante das unidades demonstram que as disciplinas podem não ter influenciado as suas formações profissionais. No entanto, elas acabaram influenciando em outros aspectos relacionados à vida dos estudantes, como podemos observar no seguinte relato: "melhora a sua condição cardiorrespiratória e há uma melhora significativa na sua disposição" (D32).

\section{Conclusão}

Frente aos resultados obtidos neste estudo, podemos concluir que os discentes trazem em suas representações sobre as disciplinas um complexo de significados, contendo representações positivas onde o objeto de estudo proporcionou de certa forma uma iniciação esportiva nos discentes, melhorando assim o condicionamento físico e, proporcionalmente, a saúde dos mesmos.

Além disto, foi possível concluir que os alunos muitas vezes trataram erroneamente as disciplinas como uma forma de lazer. Já com relação à influência na (in)formação acadêmica, identificamos que a maioria dos discentes comungam a ideia de que as disciplinas não tiveram influência na formação acadêmica, entretanto foi possível observar que alguns discentes viram as disciplinas de forma positiva.

Desta forma, concluímos que as disciplinas da forma como foram apresentadas, construíram as representações sociais dos alunos, de forma aos mesmos apresentarem em suas evocações vários aspectos que revelam que por vezes as disciplinas não foram tratadas com a importância que deveria, influenciando negativamente nas representações dos discentes. Entretanto, também foi possível constatar que as mesmas tiveram um papel importante tanto na formação acadêmica quanto em outros aspectos das vidas dos alunos. 


\section{Referências}

ALMEIDA, A. M. O. A pesquisa em representação social. Ser Social, v. 9, n. 1, p. 129-158. 2001.

AZEVEDO, D. et al. Representações sociais de RH: um estudo exploratório com alunos de graduação. Organizações \& Sociedade. Salvador: v. 19, n. 60, 2012.

BETTI, M. A Janela de Vidro. Esporte, Televisão e Educação Física. $2^{a}$ Ed. Campinas, SP: 1998.

BARDIN, L. Análise de conteúdo. Trad. Luís Antero Reto e Augusto Pinheiro. Lisboa: Edições 70, 2011.

BOURDIEU, P. Questões de sociologia. Rio de Janeiro: Marco Zero, 1983.

DE PAUlA H. E., FARIA E. L. A Educação Física no Terceiro Grau: contexto atual e perspectivas. Revista Pensar a prática, Goiânia, v.1, n.1, p. 96-105, 1998.

DUMAZEDIER J. Lazer e cultura popular.São Paulo,Perspectiva ,1973.

EL-GILANY, A H. et al. Physical activity profile of students in Mansoura University, Egypt. East Mediterr Health J. 2011 Aug;17(8):694-702

FONTANELLA, B. J. B.; RICAS, J.; TURATO, E. R. Amostragem por saturação em pesquisas qualitativas em saúde: contribuições teóricas. Cadernos de Saúde Pública, Rio de Janeiro, v. 24, n. 1, p. 17 - 27, jan. 2008.

GARBER C. E, et al. American College of Sports Medicine position stand. Quantity and quality of exercise for developing and maintaining cardiorespirator $\mathrm{y}$, musculoskeletal, and neuromotor fitness in apparently healthy adults: guidance for prescribing exercise. Med Sci Sports Exerc. 2011.

GONÇALVES, L; AZEVEDO, H, H, O. O curso de pedagogia e o processo de construção da identidade do pedagogo. Anais da $33^{a}$ Reunião anual da ANPED, GT-8: Formação de Professores, 2010.

JODELET, D. Representações sociais: um domínio em expansão. In: JODELET, Denise (org.). As representações sociais. Rio de Janeiro: EdUERJ, 2001, p. 17-44.

KOSELLECK, R. Estructuras de repetición en el lenguaje y en la historia. Revista de Estudios Políticos, Madrid, n. 134, p. 17-34./dez. 2006.

LEONTIEV, A. O Desenvolvimento do psiquismo. Lisboa: Livros Horizonte, 1978. 
MAZZOTTI, A. J. A. A Abordagem estrutural das representações sociais. Psicologia da Educação, São Paulo, n. 14/15, p.17-37, 2002.

MINAYO, M. C. S. Análise qualitativa: teoria, passos e fidedignidade. Ciência \& Saúde Coletiva, v. 17, n. 3, mar., Rio de Janeiro: 2012.

MINAYO, M. C. S.; DELANDES, S. F.; GOMES, R. Pesquisa social: teoria, método e criatividade. Petrópolis: Editora Vozes, 32ª edição, p. 110, 2012

MOSCOVICI, S. A representação social da psicanálise. Rio de Janeiro: Zahar, 1978.

MOSCOVICI, S. Representações sociais: investigações em psicologia social. Petrópolis: Vozes, 2009.

PYLRO. C. S.; ROSSETTI. C. B. Atividades Lúdicas, Gênero e Vida Adulta. Psico- USF, Bragança Paulista, n.10, v.1. p. 77-86, 2005.

SÁ, C. P. Núcleo central das representações sociais. Petrópolis, RJ: Vozes, 1998. $2^{\text {a }}$ edição.

Recebido em: 11/07/2014

Revisado em: 20/08/2015

Aprovado para publicação em: 16/10/2015

Publicado em: 30/04/2016 